\title{
Social Norms, Ideal Body Weight and Food Attitudes
}

\author{
Fabrice Etilé (INRA, France)*
}

April 11, 2007

\begin{abstract}
This paper uses French data on ideal body weight and food attitudes to analyse the role of social norms in the individual's weight control problem. A proxy measure of social norms is calculated by averaging individual perceptions of the ideal body mass index (BMI) over all observations within a reference group. Testing for different definitions of the reference group, we find that individual representations of ideal body shape are differentiated mainly along gender and age lines. Social norms regarding body shape have a significant effect on perceptions of ideal BMI only for those women who want to lose weight, with an elasticity close to 0.5. For many women and for all men, ideal BMI is almost exclusively determined by habitual BMI. Last, ideal BMI predicts a number of attitudes toward food, while social norms do not. These results suggest that promoting medical norms regarding body shape should have little effect on individual food attitudes.

JEL codes: C21, D11, D12, I10, Z13.

Keywords: obesity, body mass index, ideal weight, social norms, social interactions.
\end{abstract}

\footnotetext{
*Corresponding author: Fabrice Etilé, INRA-CORELA, 65 Boulevard de Brandebourg, 94205 Ivry-sur-Seine cedex. E-mail: etile@ivry.inra.fr. I thank Andrew Clark, Florence Jusot, Alan Warde, Frank Windmeijer, and seminar participants at the 15th European Workshop on Econometrics and Health Economics (Thessaloniki), the INRA-ALISS Workshop on Food, Health and Social Sciences, and the Journées des Economistes de la Santé Français (Dijon) for their helpful comments. I am grateful to Stephanie Scholder and two anonymous referees for very detailed comments.
} 


\section{Introduction}

Trends in body mass have recently become a major public health concern in France. In 2002, 37.5\% of French adults were overweight as against $29.7 \%$ in 1990 (OECD Health Data, 2005). ${ }^{1}$ Obesity is associated with a number of comorbidities, such as heart disease, diabete or mobility disability. This represents an increasing financial burden, taking the form of productivity losses, foregone earnings, and health care expenditures that are generally refunded by Social Security. $^{2}$ This phenomenon would seem to be an obvious arena for policy intervention through taxes, subsidies and information. However, calibrating public intervention requires that any social interactions in the consumer's weight control problem be identified, as these create social multiplier effects. In this perspective, this paper investigates social norms of body shape, using the French survey "Enquête sur les Conditions de Vie des Ménages 2001". This data set contains information on both actual body weight and height, as well as a measure of ideal body weight. Body shape is measured by the Body Mass Index (BMI). By adjusting weight for height, this yields a more precise picture of individual body shape than body weight alone, and arguably takes into consideration both medical and aesthetic concerns regarding body weight. ${ }^{3}$

Social norms designate a number of "cultural phenomena that prescribe and proscribe behaviours in specific circumstances" (Hechter and Opp, 2001, p. xi). For most economists, a norm is merely a behavioural regularity that can be measured by the mean or median behaviour within a reference group, such that any deviation from the norm results in an observable cost. Although this approach is operational, identifying social norms via behavioural regularities is questionable, as these regularities can be produced by collective habits or by a common environment which individuals within the reference group share. Avoiding a behavioural account of norms means that we have to focus on the social expectations that may or may not be behind behaviours (Bicchieri, 2005, chap. 1). In this context, we here consider a particular type of norms, called prescriptions by Akerlof and Kranton (2000). Prescriptions in a social group are shared expectations about how the group members ought ideally to behave. They produce social interactions in preferences. We ask whether and how this

\footnotetext{
${ }^{1}$ According to WHO health standards, individuals are overweight when their Body Mass Index, which equals their weight in kilograms divided by their height in meters squared, is over 25. They are obese if their BMI is over 30.

${ }^{2}$ In 1991, in France, the medical cost of obesity was about 1 billion euros (Detournay et al., 2000).

${ }^{3}$ While the BMI is a good predictor of weight-related morbidity, it does not take into account the fat/muscle distribution in the body, and might not be a good measure of body shape for some individuals. However, although the correlation between BMI and body fatness varies by age, sex, race and the level of physical activity, it remains fairly strong (Garrow and Webster, 1985, and Prentice and Jebb, 2001).
} 
type of social norm regarding body shape predicts food attitudes, and whether the norms themselves might change with actual body weight.

The empirical analysis presented here is based on three key assumptions that are motivated by findings in the psychology literature. First, a question on ideal body weight reveals information about the weight one believes one ought to have. Social norms regarding body shape are thus picked up by average ideal BMI (computed by adjusting ideal body weight for actual height) within each social group. Second, ideal body weight should maximise weight satisfaction. Third, weight satisfaction depends on social norms and on a habitual level of BMI, which captures the adjustment costs that individuals face when they want to lose weight.

We show that, under these assumptions, individuals with greater adjustment costs around their habitual BMI should declare their habitual weight as ideal. In the absence of good measures of adjustment costs, this prediction is not testable. Nevertheless, for about $39 \%$ of the sample, actual and ideal BMI coincide. As such, actual BMI would seem to be a good proxy for habitual BMI.

When adjustment costs are small around habitual BMI, ideal BMI is an explicit function of social norms and habitual BMI. We ignore those individuals who say that they would like to gain weight ( $6 \%$ of the sample), as they are more likely to have particular health problems, and test this prediction on the remaining $55 \%$ - those individuals who would like to lose weight. A linear equation specifying ideal BMI as a function of social norms, habitual BMI (which is proxied by actual BMI) and individual characteristics is estimated. As both actual BMI and social norms are likely to be endogenous, their effects are identified via instrumental variables, using the average ideal BMI of adjacent birth cohorts, years of schooling and area-level indicators as instruments. In the estimation subsample, the elasticities of individual ideal BMI to social norms and to habitual BMI are respectively about +0.5 and +0.5 for women, and zero and +0.8 for men. These are upper and lower bounds for the whole sample, and are quite sensitive to the choice of the reference group. Regarding the latter, individual representations of ideal body shape differ mainly along gender and age lines; occupation, education and other variables matter less. These estimates imply that social norms of body shape are not resistant to changes in actual body weight.

Last, the discrepancy between actual and ideal weight correlates consistently with a number of food attitudes, including the consumption of alcohol, low-fat and sugar-free products. These attitudes are generally not correlated with social norms. These results provide suggestive evidence in favour of a causal model wherein social norms and habitual BMI affect ideal BMI, which in turn influence 
food choices and ultimately actual BMI.

The paper is organised as follows. Section 2 recalls some key findings from the literature on obesity and introduces our approach to social norms. Section 3 presents the data and Section 4 discusses the economic model. Section 5 proposes an econometric specification and outlines the identification issues. Our main findings are reported in Section 6. The implications for obesity policies, as well as the limits of the analysis, appear in the concluding section.

\section{Social norms and the obesity epidemic}

\subsection{Background}

Overweight and obesity largely result from an energy imbalance between caloric intakes and expenditures. Therefore, economic explanations of the obesity epidemic have focused on the role of two factors: the fall in the full price of caloric intakes and the rise in the full price of caloric expenditures.

The full price of caloric intakes has fallen for the past forty years, because the costs of primary food products and food preparation have declined (see inter alia Cutler et al., 2003). These technological changes have favoured the growth of food consumption away from home: snacking is easier, and the density of low-price restaurants has increased. Chou et al. (2004) and Rashad et al. (2006) uncover empirical evidence of the role of the food-away-from-home sector in the U.S.. While time spent on preparing meals and eating at home has not fallen in France, time series over long periods reveal a decrease in the price of energy-dense food relative to that of fruits and vegetables (Combris et al., 2006, Warde et al., 2006). Further, there has been a dramatic increase in the supply of fast-food restaurants. Hence, the cost of a healthy diet is now much higher than that of a fat- and sugar-rich diet, which clearly contributes to the epidemic (Darmon et al., 2004; Drewnowski and Darmon, 2004).

As emphasised by Philipson and Posner (1999), while most individuals were paid to exercise in agricultural and industrial societies, this is no longer the case in post-industrial societies with public welfare. Hence, the price of caloric expenditures may have risen. While Lakdawalla and Philipson (2002) find evidence of a correlation between the fall in job-related exercise and the obesity epidemic, Cutler et al. (2003) cast some doubt on this explanation. The latter use aggregate data to show that the share of the U.S. population in energy-demanding jobs has been quite stable over the past twenty years. To our knowledge, accurate trend data in caloric expenditures are not available for France.

Empirical work has however shown that these factors explain no more than $15 \%$ of the individual variance in BMI (see the R-squared in Lakdwalla and 
Philipson, Chou et al., and Rashad et al.). Before appealing to idiosyncratic factors such as genes or personality traits, it is worth assessing the role of social interactions in the consumer's weight control problem. This paper focuses on interactions that work through social norms of body shape. This is of particular importance as norms will create a social multiplier of price and income effects if they depend on some moment of the BMI distribution (for instance the mean or the median). A fall in price will have a positive direct effect on caloric intakes, which moves the BMI distribution to the right; if this causes an increase in social norms, then the cost of over-eating will fall, and individuals will face fewer incentives to control their caloric intakes. The direct effect of a price increase is therefore multiplied via social norms.

We therefore estimate the effect of a change in the distribution of actual BMI on social norms, and document the relationship between social norms regarding body shape and food attitudes. Burke and Heiland (2005) have also argued that differences in the strength of social norms may explain the social variability in obesity trends. This paper will not test this explanation as the data are crosssectional. We will however investigate the gender differences in social norm effects.

\subsection{Measuring social norms}

The current paper is interested in a particular type of social norms, called prescriptions by Akerlof and Kranton (2000, hereafter AK). They define prescriptions as ideal characteristics that are specific to the individual's assigned social category. In AK's model, prescriptions affect identity, which in turn is an input into the individual's utility function. Drawing on extensive work in psychology, they argue that the extent to which one's own actual behaviour matches prescriptions shapes the individual's identity. Specifically, as body weight is partly under the individual's control, the model proposed in Section 4 will consider that any deviation of actual from prescribed body shape produces utility loss. Failing to conform to prescriptions thus has a cost, and as such prescriptions may produce behavioural regularities.

The traditional view in economics is that norms emerge from strategic interactions in the context of repeated games. A norm is enforced when the actions "that are compatible with the norm are supported by a Nash equilibrium" (Voss, 2001, p. 105). In this view, norms are nothing more than behavioural regularities. This approach is popular, because it does not require data on preferences or subjective beliefs: norms are mean or median behaviours. In contrast, the current paper accounts explicitly for the difference between norms as prescrip- 
tions and norms as behaviours by constructing a measure of the former from a subjective variable: ideal BMI (see Stutzer and Lalive, 2004, for a similar approach). For the rest of the paper, unless explicitly noted otherwise, the term 'social norm' will be taken as a synonym for 'prescription'.

More precisely, as noted by Elster (1989), social norms are "sustained by the feelings of embarrassment, anxiety, guilt and shame that a person suffers at the prospect of violating them". Empirical studies in social psychology have found that these feelings are associated with discrepancies between the representations of attributes individuals actually possess and the attributes they would like to possess (their 'ideal' attributes) and 'significant' others believe they ought to possess (their 'ought' attributes ; see for instance Tangney et al., 1998, or McDaniel and Grice, 2005). Hence, ideal BMI is a measure of both individual aspirations and what ought to be, and averaging ideal BMI in each social group arguably provides a proxy measure of how the individual believes s/he ought to behave, given one's group membership. We will use a geometric instead of an arithmetic average for two reasons. First, the geometric average is less sensitive to extreme values as long as the variable takes values bounded away from zero. Since our measure will be computed from the data, the social groups are small, and we do not want to put too much weight on outliers. Second, if ideal BMI is log-normal, its median is given by the geometric average. From a normative point of view, as a norm should aggregate a majority of individual preferences, a median-voter argument may apply.

The identification of social norm effects requires that the social group to which the individual is assigned be appropriately defined. We will call this latter the individual's reference group. Norms are enforced through social interactions, and the costs and consequences of interactions are generally lower the closer are individuals in social space (Horne, 2001; Akerlof, 1997). Parents, friends, work colleagues, and geographic neighbours may participate in the enforcement of norms of body shape. These 'significant' others should not be confused with the reference group, which is made up of 'similar' others. As social norms regarding body shape are sustained by social comparisons, they should take biological constraints into consideration. Hence, age and gender obviously characterise the reference group. 'Similar' others may also be those who share the same occupation, have the same education or live in the same neighbourhood. At this point, following Manski (1993), it is worth having some prior beliefs. French sociological research has suggested that occupation is the key factor driving social differentiation in body shapes and food habits (Bourdieu, 1979; Grignon

\footnotetext{
${ }^{4}$ Although a Shapiro-Francia test rejects the log-normality of ideal BMI in our data (pvalue $\left.=4 * 10^{-4}\right)$, diagnostic plots show that this is mainly due to the extreme values of the empirical distribution.
} 
and Grignon, 1999; Regnier, 2006). ${ }^{5}$ We therefore assume that individuals are similar to each other if: (i) they are of same sex; (ii) their difference in age is 5 years or less; and (iii) they belong to similar or close occupational groups. This choice is discussed at length in Section 6 .

\subsection{Comments}

Our approach to social norms calls for three comments at least.

First, in AK's model, individuals choose their actions (e.g. their body shape), taking prescriptions on body shape as given. This is closely related to the sociological concept of internalization, whereby individuals value the behaviour specified by a norm for its own sake. For classical sociology, a key consequence of internalization is that internalized norms do not require external sanctions for their enforcement (Horne, 2001). Nevertheless, AK construct a simple gametheoretic model which shows how the threat of sanctions by other members of the social group can result in an equilibrium in which prescriptions are enforced.

Second, in AK's model, individuals may suffer utility loss when other group members deviate from the social norm. As such, they allow for a specific type of social interactions called preference interactions, whereby an individual's wellbeing is directly affected by others' actions (Manski, 2000). Although the current paper adopts a restrictive version of this model, by assuming that others' actions have no direct effect on individual well-being, it will be shown in Section 4 that we remain in the general domain of preference interactions.

Third, it is tempting to interpret labour market penalties as evidence of social norm effects. For instance, Averett and Korenman (1996) and Cawley (2004) find significant wage penalties for medically obese white women in America. Using French data, Paraponaris et al. (2005) suggest that time spent in an unemployment spell is positively correlated with the body mass index. Unfortunately, these results may reflect simple statistical discrimination. Controlling one's weight may be seen as a sign of self-responsibility, and various studies have shown that being overweight is considered by recruiters and supervisors as a signal for unobservable predispositions such as laziness or lack of self-control (Puhl and Brownell, 2001). If these failings are expected to be negatively correlated with productivity, statistical discrimination can arise, especially in the race for job positions that require self-control, dynamism, and leadership. ${ }^{6}$ Moreover, these papers consider deviations from medical standards.

\footnotetext{
${ }^{5}$ For Bourdieu (1979), labour demand is an important factor of social differentiation in physical appearance: "The interest the different classes have in self-presentation [...] depend[s] on the existence of a labour market in which physical appearance may be valorized in the performance of the job itself or in professional relations; and on the differential chances of access to this market and the sectors of this market in which beauty and deportment most strongly contribute to occupational value." (p. 202).

${ }^{6}$ This may explain why the obesity wage penalty is greater in high than in low income
} 
The link between these standards and various health risks has become common knowledge over recent years. As such, some employers may partially base performance forecasts for their employees or new job applicants on their body shapes: employers' expectations alone may explain the demand for standardized body shapes. Finally, we can not always interpret labour market penalties as resulting from prescriptions. Observing sanctions in the social group to which the individual belongs would be a better identification strategy. This paper takes another route by testing whether prescriptions are a significant argument in the individual's utility function.

\section{Data}

We use data from the survey "Enquête Permanente sur les Conditions de Vie des Ménages" (EPCV2001), which was carried out by the INSEE (the French national statistical agency) in 2001. It contains information at both the household and the individual levels, and one randomly-drawn individual in each household answered a detailed health questionnaire. The starting sample consists of 5194 individuals in the same number of households. Due to missing values, 3537 individuals remain for the analysis, which uses three sets of variables: ideal and actual BMI measures; individual sociodemographic characteristics; and variables relating to food attitudes. These are presented together with descriptive statistics in Table A1 of Appendix A. ${ }^{7}$

\subsection{Ideal and actual BMIs in the data}

Both height and actual body weight are self-declared. ${ }^{8}$ Our measure of ideal body weight is based on the following question "What is the weight you would like to reach or keep?". Actual and ideal BMIs are constructed by dividing actual and ideal body weights by self-declared height squared. Their distributions are represented respectively by the solid and dashed lines in Figure A1 of Appendix A.

Actual and ideal body weights are equal for $39 \%$ of the sample; more than $55 \%$ of the sample would like to lose weight (1954 individuals); the remaining $6 \%$ would prefer to gain weight. Table A2.a shows that, among these latter, one individual is medically overweight (BMI $>25)$ and $69.3 \%$ meet the medical

\footnotetext{
occupations (Carr and Friedman, 2005). However, high income positions often come with employer-provided health insurance in the US. The obesity wage penalty may simply represent the employer's risk premium (Bhattacharya and Bundorf, 2005).

${ }^{7}$ Table A1 shows that the descriptive statistics of the analysis sample do not differ significantly from those of the starting sample: at this stage, the sample selection is random.

${ }^{8}$ We are not able to correct for declaration biases. Data with both self-reported and measured weight are not yet available for France. See Cawley (2004) for a correction procedure in U.S. data.
} 
standards for weight $(18.5 \leq \mathrm{BMI}<25)$. These individuals are more likely to have particular characteristics. For instance, they are more prone to mental disorders and negative affects: $19 \%$ of them are receiving psychiatric treatment, as against $14 \%$ in the whole sample; $25 \%$ feel lonely (vs. $15 \%$ in the whole sample), etc.

A simple inspection of Figure A1 also reveals that both tails of the actual BMI distribution are denser, and that there is less dispersion in ideal BMI than in actual BMI. Almost $72.5 \%$ of those who are satisfied with their weight meet the medical weight standards, while $19.4 \%$ are overweight $(25 \leq \mathrm{BMI}<30)$ and $3.5 \%$ are obese $(30 \leq \mathrm{BMI})$ - see Table A2.a. On the other hand, Table A2.b shows that most of the obese $(87.4 \%)$ and overweight (74.6\%) would like to lose weight (as opposed to $42 \%$ of those in the [18.5;25] range). Almost $47 \%$ of those individuals who are under the medical threshold of thinness $(\mathrm{BMI}<18.5)$ would like to gain weight, while $46 \%$ are satisfied. Hence, there is a concordance between the deviation from medical standards and weight satisfaction, which is relatively good news for public health policies.

\subsection{Social norms}

Following the discussion in Section 2, social norms are measured by taking the geometric average of ideal BMI within each reference group. Let $Q$ be the vector of variables defining group membership (age, gender and occupation), and $\Psi(Q)$ the corresponding interaction dummy. Let $W^{*}$ and $W^{g}$ denote respectively the logarithms of individual ideal BMI and social norm in reference group $g$. $\mathbb{E}\left(W^{*} \mid \Psi(Q)=g\right)$ is our measure of $W^{g}$, since it is a logarithm of a geometric average. For each individual $i, W^{g}$ is estimated by averaging $W^{*}$ over the reference group $R_{i}$ (same sex and occupation, age difference less than or equal to five years). To this end, we construct a $N \times N$ spatial weight matrix $D$, which specifies for each observation $i$ the set of similar others. This is a matrix of zeroes and ones, such that $d_{i j}=1$ if $i$ and $j$ are similar and $d_{i i}=0$. We standardize the elements of this matrix by $\sum_{j} d_{i j}$. Then the $N \times 1$ vector $\hat{W}^{g}=D W^{*}=\mathbb{E}\left(W^{*} \mid \Psi(Q)=g\right)$ contains in row $i$ a first-stage estimate of $W^{g}$ for individual $i .^{9}$

This analysis uses a social classification into 12 occupations constructed from the two-digit INSEE classification. Particular attention is paid to heterogeneity in the low and middle social classes. A distinction is made between the private and public sectors because, for a given type of activity, the level of cultural capital is generally higher (while pay is lower) in the public sector. Risk aversion

\footnotetext{
${ }^{9}$ When the reference groups are defined as in Section 2, social norms are computed using 4229 observations. The analysis sample of 3537 individuals was obtained by dropping individuals with missing values for questions about food attitudes. Reference groups containing fewer than 15 individuals are also dropped from the analysis.
} 
(and therefore the value of health) may also be higher in the public sector. The variable EMPRIV2 identifies those private sector employees in occupations where physical appearance may be more valued than education. Last, in a given age cohort, skilled and unskilled workers generally differ by qualifications and by some aspects of their lifestyles.

A simple regression of social norms $\left(\exp \left(W^{g}\right)\right)$ on age, gender and occupation dummies shows that prescribed BMI is on average higher for men than for women $(+2.2$ points of BMI). It also increases with age $(+0.06$ points of BMI per year). There is in addition a clear distinction between the lower social classes and executives. For example, those individuals who are in occupations which require or used to require some physical strength (farmers and workers) have higher prescribed BMI than executives (a difference of between 1 and 1.8 points of BMI). The prescriptions for those in the education, health or social welfare sectors, or private sector employees with administrative activities do not differ greatly from those faced by executives. This result might be explained by cultural proximity (via the level of education) or workplace proximity between these two categories (Regnier, 2006). These factors may also explain why, contrary to our first intuition, prescriptions are lower (-0.52 points of BMI) for EMPPRIV1 employees than for those employees who are in sale and customer service occupations (EMPPRIV2).

\subsection{Food attitudes}

The data also contains information on attitudes and behaviours: the frequency of exercise, the perception of diet quality (4 levels), the frequency of consumption of low-fat or sugar-free products, lower consumption of food products due to their fat or sugar content, consumption of fizzy drinks and alcohol over the previous day (see Table A1 in Appendix A). These variables are often of poor quality. For instance, there may be some reporting heterogeneity in the subjective assessment of diet quality. No distinction is made between diet and non-diet carbohydrated drinks. The frequency of exercise does not contain any information on the intensity of physical activity. As a result, the analysis is not centred around these variables. They are rather used to show that weight satisfaction consistently correlates with food attitudes (in the sense of our model's predictions).

\section{Model}

This section proposes an economic model of weight satisfaction, to guide our empirical analysis of the relationship between social norms, ideal BMI and food 
attitudes. Note that the term weight is used here but could equally be replaced by BMI or body shape.

\subsection{Weight satisfaction and ideal body weight}

The economic setting is a model in which individual utility $U($.$) is separa-$ ble into satisfaction from food $F$ and a numeraire $m, C S(F, m)$, and weight satisfaction, $W S\left(W ; W^{g}, W^{h}, W^{p}\right)$, which depends on three exogenously-given reference points: a prescription $W^{g}$, where $g$ is an index for the individual's reference group $g$; an idiosyncratic bliss point $W^{p}$; and habitual weight $W^{h}$.

Consumption goods affect BMI $W$, through a weight production equation. Given a static income constraint $\pi_{F} F+m=I$, where $I$ is income, the consumer's weight control problem is:

$$
\begin{gathered}
\operatorname{Max}_{F} U\left[C S\left(F, I-\pi_{F} F\right) ; W S\left(W ; W^{g}, W^{h}, W^{p}\right)\right] \\
W=w\left(F, I-\pi_{F} F\right)
\end{gathered}
$$

The idea underlying this model is that weight satisfaction is affected by three forces, and should decrease in the difference between actual weight and any one of the reference points. First, the need to maintain one's social identity, which is captured by $W^{g}$. This argument is at the heart of AK's model of identity and prescriptions (see Section 2). Second, the very human tendency to have private fantasies, which are captured by $W^{p}$. Anorexic symptoms are (in some cases) an extreme example of how fantasies can drive eating behaviours. Third, habituation, which is captured by $W^{h}$. Habituation appears in the form of adjustment costs, which are revealed by hypo-caloric slimming diets. During moments of high awareness, dieters generally avoid satisfying their basic caloric needs (as shown by sensations of hunger and satiety). In this case, the body interprets calorie restriction as a threat and protects its fat reserves. Then, during moments of low awareness, it sends signals that induce loss of control. Maintaining awareness has a cost, as well as lack of self-control because it damages self-esteem (Heatherton et al., 1993, Basdevant, 1998, Herman and Polivy, 2003).

A number of empirical articles in psychology have found that discrepancies between actual and ideal body size measures are positively and highly correlated with body part dissatisfaction (see for instance Cash and Green, 1986). Following Williamson et al. (1993), these results suggest that body dissatisfaction can be conceptualized as the discrepancy between perceived and ideal body sizes. Accordingly, we assume that ideal body weight (or body shape) $W^{*}$ maximises weight satisfaction: 


$$
W^{*}=\arg \max _{W} W S\left(W ; W^{g}, W^{h}, W^{p}\right)
$$

Since Sections 2 and 3 have defined $W^{g}$, the group-specific prescription, as the group average of ideal BMI, equation (2) is a model of social interactions. More precisely, preference interactions occur because the agent's preference ordering over alternative ideal body weights depends on the ideal body weights of other agents.

\subsection{Predictions}

To derive empirically tractable predictions from the model, $W S\left(W ; W^{g}, W^{h}, W^{p}\right)$ is specified as the sum of three loss functions: $v\left(W ; W^{g}\right), \Gamma\left(W, W^{h}\right)$ and $u\left(W ; W^{p}\right)$.

The cost of deviation from the social norm is captured by the sub-utility $v\left(W ; W^{g}\right)$. To reflect the idea that failing to conform to the social norm generates psychic costs, we could use any functional form $v$ such that $\partial v / \partial W \geq 0$ for $W \leq W^{g}$ and $\partial v / \partial W \leq 0$ for $W \geq W^{g}$. Further, $W$ and the prescribed behaviour $W^{g}$ should be strategic complements (i.e. $\partial^{2} v / \partial W \partial W^{g} \geq 0$ ) since, as prescribed body weight increases, the marginal disutility from lower ideal body weight should also increase for those whose ideal was already under the prescribed level. ${ }^{10}$ This paper considers a quadratic concave specification, which has the advantage of tractability and implies that the marginal utility of conformity is zero when the individual adheres perfectly to the norm.

$$
v\left(W ; W^{g}\right)=-\frac{1}{2} \gamma^{g}\left(W-W^{g}\right)^{2}
$$

Strategic complementarity requires that $\gamma^{g}$ be positive.

We also adopt a quadratic specification, $\Gamma($.$) , for adjustment costs :$

$$
\Gamma\left(W, W^{h}\right)=\left\{\begin{array}{lll}
-\left[\frac{1}{2} \gamma_{2}^{h-}\left(W-W^{h}\right)^{2}+\gamma_{1}^{h-}\left(W-W^{h}\right)\right] & \text { if } & W \leq W^{h} \\
-\left[\frac{1}{2} \gamma_{2}^{h+}\left(W-W^{h}\right)^{2}+\gamma_{1}^{h+}\left(W-W^{h}\right)\right] & \text { if } \quad W>W^{h}
\end{array}\right.
$$

The main characteristic of adjustment costs is that their right and left first derivatives may not be continuous at the habitual weight level $W^{h}: \gamma_{1}^{h+} \geq 0 \geq$ $\gamma_{1}^{h-}$. For many individuals, only losing weight is associated with adjustment costs, so that $\gamma_{2}^{h+}=\gamma_{1}^{h+}=0$, and $\gamma_{1}^{h-}<0$. Individuals with chronic illnesses such as cancer or AIDS may have trouble gaining weight: for them, $\gamma_{1}^{h+}>0$. Adjustment costs are asymmetric and may be convex, as in quitting smoking (Suranovic et al. 1999). With convex adjustment costs a small fall in caloric intakes - or equivalently in actual BMI - produces a dramatic loss of utility. Hence, the sign of $\gamma_{2}^{h-}$ is not fixed a priori.

\footnotetext{
${ }^{10}$ As emphasized by Clark and Oswald (1998), in the context of preference interactions, strategic complementarity explains following behaviours.
} 
A concave loss function $u($.$) , peaking at the individual reference point W^{p}$, captures the remaining idiosyncratic variations in ideal BMI:

$$
u\left(W ; W^{p}\right)=-\frac{1}{2} \gamma^{p}\left(W-W^{p}\right)^{2}
$$

where $\gamma^{p}$ is positive.

Let $1_{\left\{W \leq W^{h}\right\}}$ equal 1 if $W \leq W^{h}$ and 0 otherwise. Since we have quadratic functional forms, it is easily shown that $W S\left(W ; W^{g}, W^{h}, W^{p}\right)=v\left(W ; W^{g}\right)+$ $\Gamma\left(W, W^{h}\right)+u\left(W ; W^{p}\right)$ can be compactly rewritten as:

$$
W S\left(W ; W^{g}, W^{h}, W^{p}\right)=-\frac{1}{2} S(W-\widetilde{W})^{2}+c\left(W^{g}, W^{h}, W^{p}\right)
$$

where:

$$
\begin{gathered}
\widetilde{W}=\frac{1}{S}\left[\gamma^{p} W^{p}+\gamma^{g} W^{g}+1_{\left\{W \leq W^{h}\right\}}\left(\gamma_{2}^{h-} W^{h}-\gamma_{1}^{h-}\right)+1_{\left\{W>W^{h}\right\}}\left(\gamma_{2}^{h+} W^{h}-\gamma_{1}^{h+}\right)\right] \\
S=\gamma^{p}+\gamma^{g}+1_{\left\{W \leq W^{h}\right\}} \gamma_{2}^{h-}+1_{\left\{W>W^{h}\right\}} \gamma_{2}^{h+}
\end{gathered}
$$

and $c\left(W^{g}, W^{h}, W^{p}\right)$ is a function that is independent of $W$.

Suppose now that ideal body weight maximises $W S\left(W ; W^{g}, W^{h}, W^{p}\right)$. Let $W^{r e f}=\frac{\gamma^{p}}{\gamma^{p}+\gamma^{g}} W^{p}+\frac{\gamma^{g}}{\gamma^{p}+\gamma^{g}} W^{g}$. When $W^{r e f}<W^{h}$ (the most likely case), it can be shown that:

- if $-\left(\gamma^{p}+\gamma^{g}\right)\left(W^{h}-W^{r e f}\right)<\gamma_{1}^{h-}$, then the marginal cost of losing weight at $W^{h}$ is smaller than the marginal benefit from conforming to the reference BMI, $W^{r e f}$. Ideal BMI $W^{*}$ is

$$
\begin{aligned}
W^{*} & =\widetilde{W}=\frac{1}{S}\left[\gamma^{p} W^{p}+\gamma^{g} W^{g}+\gamma_{2}^{h-} W^{h}-\gamma_{1}^{h-}\right] \\
S & =\gamma^{p}+\gamma^{g}+\gamma_{2}^{h-}
\end{aligned}
$$

It is necessarily the case that $\widetilde{W}<W^{h}$.

- if $-\left(\gamma^{p}+\gamma^{g}\right)\left(W^{h}-W^{r e f}\right) \geq \gamma_{1}^{h-}$ then the marginal cost of losing weight is greater than the marginal benefit of conformity, so that ideal BMI is simply habitual BMI: $W^{*}=W^{h}$

Symmetric results hold when $W^{r e f}>W^{h}$.

The model yields three predictions. First, ideal and habitual BMI should be the same for those with high marginal adjustment costs around habitual weight. Second, equation (6) is a measurement equation that links ideal BMI to social norms and habitual BMI for all those whose habitual and ideal BMI differ. Third, assuming without loss of generality that $U=C S+W S$, the first-order condition with respect to food consumption $F$ is: 


$$
\frac{\partial C S}{\partial F}=\pi_{F} \frac{\partial C S}{\partial m}+S(W-\widetilde{W})
$$

Imagine that food consumption is measured in calories. Then, the full price of energy intake is greater than the market price for those whose actual weight is over $\widetilde{W}$. Their diet should be less caloric. ${ }^{11}$

\section{Econometric specification}

\subsection{A linear-in-means model}

The selection condition $\left(-\left(\gamma^{p}+\gamma^{g}\right)\left(W^{h}-W^{r e f}\right)<\gamma_{1}^{h-}\right)$ and equation (7) form a structural model which is not identifiable without a good measure of $W^{p}$. Nevertheless, the first prediction implies that actual BMI is a good proxy for habitual BMI, as ideal and actual BMI are equal for about $40 \%$ of the sample. ${ }^{12}$ We may hence assume that $W^{h}=W$. Then $W^{*}<W=W^{h}$ implies that $W^{*}=\widetilde{W}$, as in equation (7). The latter provides a starting point for specifying the relationship between ideal BMI and social norms in the subsample of those who would like to lose weight: this will be our estimation sample, whose descriptive statistics are presented in Table A1 of Appendix A. For this subsample:

$$
W^{*}=\underbrace{\frac{\gamma^{g}}{\gamma^{p}+\gamma^{g}+\gamma_{2}^{h-}}}_{\alpha^{g}} W^{g}+\underbrace{\frac{\gamma_{2}^{h-}}{\gamma^{p}+\gamma^{g}+\gamma_{2}^{h-}}}_{\beta^{g}} W+\underbrace{\frac{\gamma^{p}}{\gamma^{p}+\gamma^{g}+\gamma_{2}^{h-}}}_{1-\alpha^{g}-\beta^{g}} W^{p}-\gamma_{1}^{h-}
$$

The key implication of this model is that the regressions will have to control for $W$, which proxies habitual weight, in order to estimate correctly the social norm effect $\alpha^{g}$. Note also that, ceteris paribus, the lower is $\gamma^{g}$, the less likely it is that the selection condition $-\left(\gamma^{p}+\gamma^{g}\right)\left(W^{h}-W^{r e f}\right)<\gamma_{1}^{h-}$ holds. Hence, estimating (9) in the selected subsample will yield an upper bound for the size of the social norm effect $\alpha^{g}$ over the whole sample.

Using the notation introduced in Section 3, the variables $W, W^{*}$ and $W^{g}$ are the logarithms of actual BMI, ideal BMI and social norms, and $\mathbb{E}\left(W^{*} \mid \Psi(Q)=g\right)$ is our measure of $W^{g}$ for the reference group $g .{ }^{13}$ Since $W^{g}$ takes only one value

\footnotetext{
${ }^{11}$ All predictions hold under one regularity condition: that adjustment costs are not downward sloping for all $W<W^{h}$. Hence, $\gamma_{2}^{h-}$ should not be too negative. This condition also implies that $S$ is positive in equation (7).

${ }^{12}$ Another obvious reason is that there are measurement errors ('heaping' effects for instance) in answers to questions about ideal body weight.

${ }^{13}$ Note that while the estimation subsample does not include individuals whose ideal and actual BMIs are equal, all available observations were used in Section 3 for the construction of $\hat{W}^{g}$.
} 
within group $g$, we have to impose the identifying restriction that $\forall g, \alpha^{g}=\alpha$ and $\beta^{g}=\beta$ in equation (9).

The idiosyncratic reference point $W^{p}$ is a function of observable and unobservable individual characteristics. Let $H$ represent the individual variables that might affect perceptions of ideal body shape (such as income, area of residence, marital status etc.); $\mathbb{E}(H \mid \Psi(Q)=g)$ are contextual effects, whereby individuals have similar perceptions due to average within-group observable characteristics. ${ }^{14}$ We assume that:

$$
\left(1-\alpha^{g}-\beta^{g}\right) W^{p}-\gamma_{1}^{h-}=\bar{\delta} \mathbb{E}(H \mid \Psi(Q)=g)+\delta H+\eta
$$

where $H$ includes the constant and $\eta$ is an error-term with mean zero that captures unobservable individual effects.

The econometric counterpart of equation (9) is:

$$
W^{*}=\alpha \mathbb{E}\left(W^{*} \mid \Psi(Q)=g\right)+\beta W+\bar{\delta} \mathbb{E}(H \mid \Psi(Q=g))+\delta H+\eta
$$

When $\eta$ is correlated with $\Psi(Q)$ (i.e. $\mathbb{E}(\eta \mid \Psi(Q)=g) \neq 0$ ), we have correlated effects, whereby agents in the same group behave similarly because they have "similar unobserved characteristics or face similar institutional environments" (Manski, 1993). In this paper we are more interested in the endogenous effect $(\alpha)$ produced by social norms and preference interactions. Testing for the significance of $\alpha$ amounts to testing whether deviations from prescribed BMI have an effect on weight satisfaction.

The difference between endogenous and correlated effects can be illustrated as follows. Consider the social group of teenage girls, and suppose that their perceptions of ideal body size is influenced by fashion models. Banning waiflike models from the catwalk will then have a positive impact on teenagers' perceptions. The ideal BMI of all group members will tend to rise, and so will $W^{g}$. Hence, $W^{*}$ and $W^{g}$ may covary even though a change in $W^{g}$ has no direct effect $(\alpha=0)$. Disentangling endogenous effects from correlated effects is important for public policy, as the former are associated with social multipliers, while the latter are not. This distinction does however bring up substantial identification problems, as correlated effects render $W^{g}=\mathbb{E}\left(W^{*} \mid \Psi(Q)=g\right)$ endogenous.

\subsection{Identification issues}

Specification (10) raises a number of identification issues (see the discussion in Manski, 1993). First, taking expectations of (10) with respect to $\Psi(Q)$ reveals

\footnotetext{
${ }^{14}$ Imagine for instance that there is some segregation by social group on the marriage market. Then, ideal body weight in a group may depend on the average rate of singles, which will reflect how competitive the group-specific marriage market is.
} 
that $\mathbb{E}\left(W^{*} \mid \Psi(Q)\right)$ is a function of $\mathbb{E}(H \mid \Psi(Q))$ (as well as $\mathbb{E}(\eta \mid \Psi(Q))$ if there are correlated effects). These variables are collinear and the effect of $\mathbb{E}\left(W^{*} \mid \Psi(Q)\right)$ is not identifiable without further assumptions. As it is often the case in models of social interactions, we assume that there are no contextual effects: $\bar{\delta}=0$. The model then becomes:

$$
W^{*}=\alpha \mathbb{E}\left(W^{*} \mid \Psi(Q)=g\right)+\beta W+\delta H+\eta
$$

Second, the model is identified if $\mathbb{E}(\eta \mid \Psi(Q))=0$ (no correlated effects). As this is unlikely to be the case (at least because contextual effects are omitted), we have to instrument $\hat{W}^{g}=D W^{*}=\mathbb{E}\left(W^{*} \mid \Psi(Q)\right)$. Actual weight may also be endogenous $(\mathbb{E}(\eta \mid W) \neq 0)$, if unobservable factors such as fascination with fashion models simultaneously affect actual and ideal body weight.

We therefore estimate equation (11) by a Generalized Method of Moments (GMM) which exploits the orthogonality conditions between the residuals and a set of instruments. These latter include the prescriptions in adjacent reference groups (following Grodner and Kniesner, 2006). More precisely, consider an individual $i$ of age $A_{i}$. All of the same sex and occupation individuals $j$, with age $A_{j}$ such that $A_{i}-5 \leq A_{j}<A_{i}$ belong to this reference group, $R_{i}$. Then, same sex and occupation individuals $k$ such that $A_{j}-5 \leq A_{k}<A_{i}-5$ belong to $R_{j}$, but not to $R_{i}$. Averaging social norms over these individuals $k$ produces a variable $W^{g-}$ that should be correlated with the ideal BMI of $j$ individuals, and therefore with $i$ 's prescription. Conditional on the latter, $W^{g-}$ should not be correlated with $W^{*} .{ }^{15}$ Symmetrically, we can construct $W^{g+}$ by using individuals $k$ such that $A_{i}+5<A_{k} \leq A_{j}+5$ for all of the $j \mathrm{~s}$ in $R_{i}$. According to (11) current actual BMI may influence future ideal BMI. We hence expect $W^{g+}$ to be correlated with $W$.

We also use two geographical instruments in an attempt to capture factors (prices, quality of food supply, deprivation etc.) that may affect actual BMI. These include the mean prevalence of obesity (MOBESE) and dental problems (MDENTS) across individuals living in the same or adjacent geographical region (department), and the same or close types of residential area. ${ }^{16}$ The mean prevalence of obesity is estimated from the data (using all available information), while the mean prevalence of dental problems is estimated from the five yearly

\footnotetext{
${ }^{15}$ For instance, the ideal BMI of a 40-year old male skilled worker should be influenced only by the prescription $W^{g 1}$ for this group, and not by the prescription $W^{g 2}$ for 34 -year old male skilled workers. However, $W^{g 1}$ and $W^{g 2}$ both depend on the ideal BMI of the male skilled workers aged between 35 and 39. They should therefore be correlated. This is similar to the instrumentation of a variable by its lagged values in the panel data analysis of dynamic models.

${ }^{16}$ France is divided into 95 departments, and there are 5 types of residential area (STRAT1STRAT5 in Table A1 of Appendix A). We assume that STRAT $k$ and STRAT $k+1$ are close, while STRAT $k-1$ and STRAT $k+1$ are distant.
} 
surveys "Enquête sur les Conditions de Vie des Ménages 1996-2000". These instruments should not be correlated with ideal BMI conditional on actual BMI. This may also be the case for years of schooling (YRSCHOOL, computed using the OECD equivalence scale for French education).

For robust identification, the instruments should be strongly correlated with social norms and actual BMI, conditional on the other variables affecting ideal BMI. We evaluate instrument power using the Cragg-Donald statistic (CD) as suggested by Stock and Yogo (2002). Under a normality assumption, this statistic generalises the F-statistic from the first-stage regression when there is more than one endogenous variable. Conservative critical values are calculated by Stock and Yogo under the null that the instruments are weak. We also use an Anderson-Rubin statistic (AR), which tests the null that the instruments are jointly insignificant in a reduced form version of (11) in which they replace the endogenous regressors. Last, we always use more than two instruments. As such, the model is over-identified and the over-identifying restrictions are tested via a Hansen test. The regressions use the instrument sets that maximise CD and $\mathrm{AR}$, and minimise the Hansen statistic.

\section{Results}

Central to the model is the assumption that prescriptions do not affect behaviours directly, but rather operate through ideal body shape. From equation (8), we should then observe a positive correlation between $\left(W-W^{*}\right)$ and healthy food attitudes for those individuals who want to lose weight (since for them $\left.W^{*}=\widetilde{W}\right)$. The reverse should hold for those who want to gain weight. Before estimating equation (11), we show that the difference between actual and ideal BMI predicts a number of food attitudes.

\subsection{Ideal body weight as a predictor of food attitudes}

Controlling for a number of variables (income, education, age, sex, occupation and region), we estimate probit and ordered probit models of the attitude variables as a function of five explanatory variables: $W$, the logarithm of height, social norms, $O V E R W$ and $U N D E R W$. These last two variables will capture any asymmetric effects of deviations from ideal BMI:

$$
\begin{aligned}
U N D E R W & =1_{\left\{W \leq W^{*}\right\}}\left(W^{*}-W\right) \\
O V E R W & =1_{\left\{W^{*}<W\right\}}\left(W-W^{*}\right)
\end{aligned}
$$


The variable $U N D E R W$ is desired weight gain for those who feel underweight; $O V E R W$ is desired weight loss for those who feel overweight.

Table B1 in Appendix B shows the results. Given actual BMI, dissatisfaction with BMI is positively correlated with reporting an unhealthy diet (see the coefficients on $O V E R W$ and $U N D E R W)$. We should also observe a positive relationship between $O V E R W$ and healthy attitudes: the more I want to lose weight, the healthier my food habits should be. The reverse should hold for those who want to gain weight.

Those who feel overweight are more likely to avoid the consumption of certain food products, and consume more often low-fat or sugar-free products (see the coefficients on $O V E R W)$. Their consumption of alcohol over the past 24 hours is lower. Opposite or insignificant results are found for those who feel underweight (see the coefficients on $U N D E R W$ ). Interestingly, there are no significant correlations between weight satisfaction and exercise, and those who want to lose weight do not drink significantly fewer fizzy drinks. This could reflect the poor quality of the data. Nevertheless, the results suggest that ideal BMI captures information about individual preferences that are not captured by actual BMI. Moreover, given weight satisfaction and actual weight, our measure of social norms regarding body shape attracts only two significant coefficients. This is suggestive evidence that social norms may only indirectly affect behaviour, through individual perceptions of ideal body weight.

\subsection{The effect of social norms on ideal body weight}

Table B2 in Appendix B reports the main results. The econometric method is indicated in the first row. ${ }^{17}$ The coefficients on social norms or actual BMI are elasticities.

The first column (OLS/1) shows OLS results from the specification which controls only for the $H$ variables. Men have a higher ideal BMI than women $(+11 \%)$, as expected, and the age effect is positive and concave. The occupation dummies are generally insignificant, but lower social classes and farmers seem to have a higher ideal BMI than managers. There is also a negative education effect, which disappears when actual BMI is introduced, as shown by the OLS results in the second column (OLS/2). This specification also controls for social norms. Here, the gender effect is weaker, the age effect is no longer significant, and the social gradient is somewhat reversed. The elasticity of ideal BMI to the social norm is positive and small, but significant $(+0.13)$, while the elasticity to actual BMI is relatively high $(+0.64)$

\footnotetext{
${ }^{17}$ All instrumental variables results were obtained using the Stata procedure ivreg2 (Baum et al., http://fmwwc.bc.edu/repec/bocode/i).
} 
Age, sex and occupation are dropped in the third specification, which is estimated by GMM using YRSCHOOL, MDENTS, $W^{g-}$ and $W^{g+}$ as instruments $(\mathrm{GMM} / 3)$. As shown by the p-value of the AR statistic, the model is not underidentified in the sense that, absent controls for social norms and actual BMI, the instrument set is significantly correlated with ideal BMI. The p-value of the Hansen over-identification test is correct, although not very high. Perhaps more worrying is the CD statistic of 4.2. According to Stock and Yogo (2002, Table 1), this corresponds to a bias of the GMM estimator relative to OLS of about 30\%. GMM does better than OLS but the results are still biased. The elasticity regarding social norms is much higher than in OLS/2 $(+0.78)$, while the effect of actual BMI is cut in half $(+0.27) \cdot{ }^{18}$ Individual characteristics play a minor role here, because actual BMI captures most of their influence. However, we find a significant negative effect of single-parenthood: in any given social group, single-parents have a lower ideal body weight. One appealing explanation is in terms of value on the re-marriage market: thinness may compensate for the presence of children.

The fourth specification drops actual BMI (GMM/4). Here, all the tests pass easily. As such, the problem of weak identification in specification GMM/3 came from the lack of strong instruments for actual BMI. However, specification GMM/4 is open to the "tautological identification" criticism (Manski, 1993, section 2.4). With actual BMI being excluded, no individual control variables are significantly correlated with ideal BMI. This fourth specification can then be thought of as a regression of ideal BMI on its mean, and it is unsurprising that the elasticity is close to 1 .

The fifth specification adds controls for age, gender and occupation to specification 3. We aim here to identify the effect of the variables $Q$, by relying on non-linearities between the $Q$ variables (age, gender and occupation), and social norms $\mathbb{E}\left(W^{*} \mid \Psi(Q)\right)$. Neither the $Q$ nor the social norm variables attract positive coefficients, as there is a considerable amount of collinearity between

\footnotetext{
${ }^{18}$ The positive OLS bias on actual weight can be explained by unobservable taste factors: for instance, taste for fitness and exercise, or vegetarianism should be negatively correlated with both actual and ideal BMIs. The increase in the coefficient of the social norm is harder to explain, as the OLS bias is usually positive in social interactions models. This prediction does not hold here for two reasons: (i) actual weight and the social norm are both endogenous; (ii) we estimate the model in a sub-sample of the population. To illustrate (ii), consider for instance the unobservable variable "watching television" $(T V)$. $T V$ is likely to have a positive effect on actual weight $W$ in the weight production equation. If it has also a negative effect on the idiosyncratic bliss-point $W^{p}$, then the sign of the effect of $T V$ on the social norm $W^{g}$ will be ambiguous. An increase in $T V$ will increase the probability of being dissatisfied. Hence, in each social group, fewer individuals will declare their actual weight to be ideal. But this negative effect on ideal body weight may be offset by a positive effect on the actual weight of those who remain satisfied. The total effect on $W^{g}$ may therefore be positive or negative. If it is positive, then $T V$ will be positively correlated with $W^{g}$ and negatively with $W^{*}$, which biases negatively the OLS estimate of the social norm effect.
} 
the former and the latter. ${ }^{19}$ As such, although the CD statistics are almost the same in GMM/3 and GMM/5, GMM/3 is our preferred specification.

We find a remarkably high elasticity of ideal BMI to the social norm (about 0.7). But this is clearly an upper bound for the true elasticity in the whole population, as only the subsample of individuals for whom, according to the model, social norms matter, was selected. The structural model implies that this elasticity is 0 for those with high marginal adjustment costs. However, the results are neither robust nor precise, as shown by the specification tests. Further, we may wonder whether the social norm effect varies by gender and the extent to which it is sensitive to the definition of the reference group.

\subsection{Alternative specifications}

Table B3 presents estimation results of our preferred specification (GMM/3) for men and women separately. It tests various definitions of the reference group. For each definition, the coefficients of interest are displayed in the first and second rows. The test statistics are reported in the next three rows. The number of observations and the instrument set are found in the last two rows. ${ }^{20}$

The benchmark results are reported in the upper part of the Table, for reference groups comprising same sex and same occupation individuals with less than 5 years of age difference. Perhaps the most striking result is that the elasticity to social norms is about +0.7 for women, but negative and insignificant for men. For women, the results are more robust than before, since the CD statistic shows that the bias of GMM relative to OLS is about $20 \%$. There is clearly an important problem of weak identification in the subsample of men. The estimates do not change particularly as the maximum age difference increases from 2 , to 5 , and even 10 years (see the first and second rows in the upper part of the Table). There is more variation for men, but the Hansen statistic rejects the overidentifying restrictions ( $\mathrm{p}$-value: $2 e^{-4}$ ) when the maximum age difference is set to two years.

We then model social stratification by seven education levels instead of twelve occupation groups. ${ }^{21}$ The results reported in the middle part of Table B3 change only little, so that education and occupation are interchangeable indicators. We can ask whether the socioeconomic stratification makes any difference.

The lower part of the Table presents our most robust results. The reference group is defined on the basis of only age and gender. As previously, the elasticity

\footnotetext{
${ }^{19}$ Regressing $\mathbb{E}\left(W^{*} \mid \Psi(Q)\right)$ on $Q$ produces a R-squared of 0.91 .

${ }^{20}$ Since we only keep groups with more than 15 individuals, the number of observations varies with the definition of the reference group.

${ }^{21}$ The seven education levels are: no qualifications, primary school, general secondary school, vocational secondary school, Baccalaureat $(\simeq \mathrm{A}$-level), Baccalaureat +2 years, more than 2 years after the Baccalaureat.
} 
to social norms is insignificant for men, but somewhat lower for women $(+0.52)$. All test statistics are satisfactory. In particular, the CD statistic for women is around 8.5, which means that the bias of GMM relative to OLS is under $10 \%$. The CD statistic for men is close to 5.2 , so that the relative bias is about $20 \%$. To illustrate these results, for a $1.70 \mathrm{~m}$ woman who weighs $65 \mathrm{kgs}$, and whose ideal weight is $60 \mathrm{kgs}$, a $1 \mathrm{~kg}$ increase in actual weight should result in a 0.45 $\mathrm{kg}$ increase in ideal weight. The corresponding increase is $0.72 \mathrm{kgs}$ for a man with the same initial characteristics. For a woman, if the prescribed weight was initially $60 \mathrm{kgs}$ and increases by $1 \mathrm{~kg}$, the corresponding increase in the perception of ideal body weight is almost $0.5 \mathrm{kgs}$. These estimates also imply that there is no social multiplier for men, while the upper bound on the social multiplier is 1.1 for women. Hence, a price change that increases the actual BMI of all women by $1 \%$, would directly increase their ideal BMI by at least $0.49 \%$ and indirectly, via the social multiplier, by at most $0.54 \%$ (i.e. 0.49 times the social multiplier). The same policy would increase men's ideal BMI by $0.78 \%$. Last, the absence of social interactions for men is not surprising, as a number of empirical studies have generally found that the social prescriptions on body shape are more saliant and have a greater effect for women (see for instance Cash and Brown, 1989, or Paquette and Raine, 2005).

\section{Conclusion}

One of the major objectives of public health policy over recent years has been the reduction of overweight and obesity. It has been suggested that taxes and subsidies on food products, as well as the dissemination of information and nutritional labelling may help to achieve this objective. In this perspective, assessing the role of social norms of body shape is crucial, since they will act as social multipliers on the effect of public policies. The intuition in the paper was that the effect of social norms is mediated by individual perceptions of ideal body shape.

We find that weight satisfaction is significantly correlated with a number of attitudes toward food, with the expected signs. There are few direct correlations between food attitudes and social norms. Social norms therefore do not directly act on consumption behaviours, but rather indirectly, by modifying individual aspirations.

Social norms have a significant effect on ideal body shape only for those women who want to lose weight, with an elacticity close to 0.5 . If social norms were to remain fixed, then these elasticities would be good news. However, this result is an upper bound and men are not sensitive to social norms. Further, the elasticity of ideal BMI to habitual BMI is at least 0.3 for women, and over 
0.8 for men. The habituation of individual representations to the reality is important and, in fine, moves social norms upward. There are two consequences. First, the autocorrelation of ideal BMI in social groups is mainly due to correlated effects rather than to endogenous effects. Second, the social multiplier effect plays a minor role compared to the habituation effect, whereby individual aspirations regarding weight adapt to the individual's habitual weight. Last, obesity increased faster for women (+64\%) than for men (+40\%) between 1997 and 2006, according to the ObEpi-Roche survey. Although we are unable to estimate the effect of ideal BMI on actual BMI, these figures are consistent with our finding that the social multiplier matters only for women. It may then be useful to promote appropriate norms of thinness by information campaigns targeted at women.

As noted by Manski (1993), appealing to global anonymous interactions in large reference groups a priori hinges on how the group of 'similar' others is defined. While age and gender are important stratification variables, this is not the case for socioeconomic indicators. This suggests two directions for future research. First, individuals may base their weight representations on role models (pop stars, sportsmen or women, etc.). This is certainly the case for teenagers, but there is only scarce evidence for adults, and here ethnographic studies may be helpful. Second, studies of interactions in small groups are wanting. Since it has been shown in the case of smoking that interactions within small groups (peer effects) are often only small, we may wonder whether the same holds for the individual's weight control problem.

\section{References}

[1] Akerlof, G.A. (1997), "Social Distance and Social Decisions", Econometrica, 65, 1005-1027.

[2] Akerlof, G.A. and Kranton, R.E. (2000), "Economics and Identity", Quarterly Journal of Economics, 115, 715-754.

[3] Averett, S. and Korenman, S. (1996), "The Economic Reality of The Beauty Myth", The Journal of Human Resources, 31, 304-330.

[4] Basdevant, A. (1998), "Sémiologie et clinique de la restriction alimentaire", Cahiers de Nutrition et de Diététique, 33, 235-241.

[5] Bhattacharya, J. and Bundorf, M.K. (2005), "The Incidence of the Healthcare Costs of Obesity", National Bureau of Economic Research, Working Paper $n^{\circ} 11303$. 
[6] Bicchieri, C. (2006), The Grammar of Society: the Nature and Dynamics of Social Norms, Cambridge: Cambridge University Press.

[7] Bourdieu, P. (1979)[1987], La distinction [Distinction: A Social Critique of the Judgement of Taste], Paris: Editions de Minuit [Harvard University Press].

[8] Burke, M.A. and Heiland, F. (2005), "Social Dynamics of Obesity", Center on Social and Economic Dynamics Working Paper Series $\mathrm{N}^{\circ} 40$.

[9] Cawley, J. (2004), "The Impact of Obesity on Wages", The Journal of Human Resources, 39, 451-474.

[10] Cash, T.F. and Green, G.K. (1986), "Body weight and body image among college women: perception, cognition, and affect", Journal of Personality Assessment, 50, 290-301.

[11] Cash T.F. and Brown T.A. (1989), "Gender and body images: stereotypes and realities.", Sex Roles, 21, 361-373.

[12] Chou, S-Y., Grossman, M. and Saffer, H. (2004), "An economic analysis of adult obesity: results from the Behavioral Risk Factor Surveillance System", Journal of Health Economics, 23, 565-587.

[13] Clark, A.E. and Oswald, A.J. (1998), "Comparison-concave utility and following behaviour in social and economic settings", Journal of Public Economics, 70, 133-155.

[14] Combris, P., Etilé, F. and Soler, L-G. (2006), "Alimentation et Santé: changer les comportements de consommation ou mieux réguler l'offre alimentaire", in Désirs et peurs alimentaires au XXIème siècle (Proust I. ed.), Paris: Dalloz, 203-261.

[15] Cutler, D., Glaeser, E. and Shapiro, J.M. (2003), "Why have Americans become more obese?", Journal of Economic Perspectives, 17, Summer 2003, pp. 93-118.

[16] Darmon, N., Ferguson, E.L. and Briend, A. (2002), "A Cost Constraint Alone Has Adverse Effects on Food Selection and Nutrient Density: An Analysis of Human Diet by Linear Programming", Journal of Nutrition, 132, 3764-3771.

[17] Detournay, B., Fagnani, F., Phillippo, M., Pribi, C., Charles, M.A., Sermand, C., Basdevant, A. and Eschwege, E. (2000). "Obesity, morbidity and health care costs in France: an analysis of the 1991-1992 Medical Care Household Survey", International Journal of Obesity, 24, 151-155.

[18] Drewnowsky, A. and Darmon, N. (2004), "Replacing Fats and Sweets With Vegetables and Fruits - A question of Cost", American Journal of Public 
Health, 94, 9, 1555-1559.

[19] Elster, J. (1989), "Social Norms and Economic Theory", Journal of Economic Perspectives, 3, 99-117.

[20] Garrow, J.S. and Webster, J. (1985), "Quetelet's index (W/H2) as a measure of fatness", International Journal of Obesity, 9, 147-153

[21] Grignon, C. and Grignon, Ch. (1999), "Long-Term Trends in Food Consumption: a French Portrait", Food and Foodways, 8, 151-174.

[22] Grodner, A. and Kniesner, T. (2006), "Labor Supply with Social Interactions: Econometric Estimates and Their Tax Policy Implications", Center for Policy Research Working Papers $n^{\circ} 69$.

[23] Heatherton, T.F., Polivy, J., Herman, C.P. and Baumeister, R.F. (1993), "Self-Awareness, Task Failure, and Disinhibition: How Attentional Focus Affects Eating", Journal of Personality, 61, 49-61.

[24] Hechter, M. and Opp, K-D. (2001), Social Norms, New York: Russell Sage Foundation.

[25] Herman, C.P. and Polivy, J. (2003), "Dieting as an Exercise in Behavioral Economics", in Time and Decision (Loewenstein G., Read D., Baumeister R.F. eds), New York: Russell Sage Foundation,459-489.

[26] Horne, C. (2001), "Sociological perspectives on the emergence of norms", in Social Norms (Hechter M. and Opp K-D., eds) New York: Russell Sage Foundation, 3-34.

[27] Manski, C.F. (1993), "Identification of Endogenous Social Effects: The Reflection Problem", Review of Economic Studies, 60, 531-542.

[28] Manski, C.F. (2000), "Economic Analysis of Social Interactions", Journal of Economic Perspectives, 14, 115-136.

[29] McDaniel, B.L. and Grice, J.W. (2005), "Measuring self-discrepancies on the big five personality traits with the repertory grid", Personal Construct Theory and Practice, 2, 18-32.

[30] Paquette, M-C. and Raine, K. (2004), "Sociocultural context of women's body image", Social Science $\&$ Medicine, 59, 1047-1058.

[31] Philipson, T.J. and Posner, R.A. (1999), "The long-run growth in obesity as a function of technological change", National Bureau of Economic Research, Working Paper No.7423.

[32] Prentice, A.M. and Jebb, S.A. (2001), "Beyond body mass index", Obesity Reviews, 2, 141-147. 
[33] Puhl, R. and Brownell, K.D. (2001), "Bias, Discrimination and Obesity", Obesity Research, 9, 788-805.

[34] Rashad, I., Grossman, M. and Chou S-Y. (2006), "The Super Size of America: An Economic Estimation of Body Mass Index and Obesity in America", Eastern Economic Journal, 32, 133-148.

[35] Régnier, F. (2006), "Obésité, corpulence et souci de minceur: inégalités sociales en France et aux Etats-Unis", Cahiers de Nutrition et Diététique, 41, 97-103., 383-413.

[36] Suranovic, S.M., Goldfarb, R.S. and Leonard T.C. (1999), "An economic theory of cigarette addiction", Journal of Health Economics, 18: 1-29.

[37] Stock, J.H. and Yogo, M. (2002), "Testing for Weak Instruments in Linear IV Regression", NBER Technical Working Paper $\mathrm{n}^{\circ} 284$, revised version available online at http://ksghome.harvard.edu/ JStock/ams/websupp/wi_papers.htm.

[38] Stutzer, A. and Lalive, R. (2004), "The Role of Social Work Norms in Job Searching and Subjective Well-Being.", Journal of the European Economic Association, 2, 696-719.

[39] Tangney, J.P., Niedenthal, P.M., Covert, M.V. and Barlow, D.H. (1998), "Are Shame and Guilt Related to distinct Self-Discrepancies? A Test of Higgins's (1987) Hypotheses", Journal of Personality and Social Psychology, 75, 256-268.

[40] Voss, T. (2001), "Game-theoretical perspectives on the emergence of social norms.", in Social Norms (Hechter M. and Opp K-D., eds) New York: Russell Sage Foundation, 105-136.

[41] Warde, A., Cheng, S-L., Olsen, W., and Southerton, D. (2006), "Changes in the practive of eating: a comparative analysis of time-use", Acta Sociologica, forthcoming.

[42] Williamson, D.A., Gleaves, D.H., Watkins, P.C. and Schlundt, D.G. (1993), "Validation of self-ideal body size discrepancy as a measure of body dissatisfaction", Journal of Psychopathology and Behavioral Assessment, $15,57-68$. 


\section{Appendix A. Summary statistics}

$\underline{\text { Table A.1. - Name and variable definition }}$

\begin{tabular}{|c|c|c|c|c|}
\hline Name & Definition & \multicolumn{3}{|c|}{ Mean (s.d.) or \% } \\
\hline \multicolumn{2}{|r|}{ Sample } & $\begin{array}{c}\text { Starting } \\
\text { sample } \\
(\mathrm{N}=5194) \\
\end{array}$ & $\begin{array}{l}\text { Analysis } \\
\text { sample } \\
(\mathbf{N}=3537) \\
\end{array}$ & $\begin{array}{c}\text { Estimation } \\
\text { sample } \\
(\mathbf{N}=\mathbf{1 9 5 4}) \\
\end{array}$ \\
\hline WEIGHT & Self-declared actual body weight & $68.53(14.06)$ & $\begin{array}{c}68.91 \\
(14.13)\end{array}$ & $72.88(14.25)$ \\
\hline IDEALWEIGHT & Ideal body weight & $65.45(11.98)$ & $\begin{array}{c}65.43 \\
(12.04)\end{array}$ & $66.03(11.91)$ \\
\hline HEIGHT & Height (in m) & $1.67(0.09)$ & $1.67(0.09)$ & $1.66(0.09)$ \\
\hline BMI & $\begin{array}{l}\text { Self-declared body weight in kg divided by height in meters } \\
\text { squared }\end{array}$ & $24.36(4.18)$ & $24.65(4.21)$ & $26.26(4.13)$ \\
\hline IDEALBMI & $\begin{array}{l}\text { Self-declared ideal body weight in kg divided by height in } \\
\text { meters squared }\end{array}$ & $23.23(3.15)$ & $23.37(3.16)$ & $23.76(3.05)$ \\
\hline SEX & $=1$ if male, $=0$ otherwise & $44.0 \%$ & $41.2 \%$ & $34.4 \%$ \\
\hline AGE & Age & $49.06(19.21)$ & $\begin{array}{c}50.58 \\
(16.24) \\
\end{array}$ & $49.85(15.38)$ \\
\hline INCMIN & $\begin{array}{l}\text { Minimum yearly net household income adjusted by the } \\
\text { number of consumption unit (OECD scale), in } 2001 \text { French } \\
\text { Francs }\end{array}$ & $\begin{array}{l}137432.4 \\
(85146.8)\end{array}$ & $\begin{array}{l}138559.9 \\
(84938.8)\end{array}$ & $\begin{array}{l}144181.6 \\
(85779.9)\end{array}$ \\
\hline \multicolumn{5}{|c|}{\begin{tabular}{|l} 
EDUCATION \\
\end{tabular}} \\
\hline YRCHOOL & Years of schooling (OECD equivalence scale) & $8.84(5.50)$ & $9.04(5.47)$ & $9.37(5.32)$ \\
\hline \multicolumn{5}{|c|}{ STANDARD OCCUPATIONAL CLASSIFICATION (SOC) } \\
\hline FARMERS & Farmers and farm managers & $5.0 \%$ & $4.5 \%$ & $3.4 \%$ \\
\hline OWNERS & Small business owners (mainly in skilled trade occupations) & $5.8 \%$ & $6.3 \%$ & $6.4 \%$ \\
\hline EXECUTIVES & $\begin{array}{l}\text { Public and private sector executives (include other business } \\
\text { owners, managers in the public and industrial sectors, } \\
\text { professionals in the private sector, upper categories in the } \\
\text { teaching, culture and media sectors) (reference). }\end{array}$ & $11.0 \%$ & $13.1 \%$ & $13.6 \%$ \\
\hline MIDPUB1 & $\begin{array}{l}\text { Teachers, professional occupations in the health and social } \\
\text { welfare sectors (nurses, community workers, etc.) }\end{array}$ & $7.1 \%$ & $7.9 \%$ & $8.3 \%$ \\
\hline MIDPUB2 & $\begin{array}{l}\text { Associate professional and technical occupations in the } \\
\text { public sector (police officer etc.) }\end{array}$ & $5.3 \%$ & $5.6 \%$ & $6.5 \%$ \\
\hline MIDPRIV & $\begin{array}{l}\text { Associate professional and technical occupations in the } \\
\text { private sector (technician etc.) }\end{array}$ & $5.4 \%$ & $5.2 \%$ & $4.4 \%$ \\
\hline EMPPUB & $\begin{array}{l}\text { Administrative, secretarial and personal service occupations } \\
\text { in the public sector without management responsibilities } \\
\text { (nursing assistant, policeman etc.) }\end{array}$ & $9.6 \%$ & $11.7 \%$ & $12.9 \%$ \\
\hline EMPPRIV1 & $\begin{array}{l}\text { Administrative, secretarial and personal service occupations } \\
\text { in the private sector without management responsibilities } \\
\text { (company secretary etc) }\end{array}$ & $8.5 \%$ & $9.6 \%$ & $11.3 \%$ \\
\hline EMPPRIV2 & $\begin{array}{l}\text { Sale and customer service occupations in the private sector } \\
\text { without management responsibilities (retail cashiers etc.) }\end{array}$ & $10.2 \%$ & $11.2 \%$ & $11.9 \%$ \\
\hline SKWORK1 & Skilled workers & $10.4 \%$ & $11.6 \%$ & $9.9 \%$ \\
\hline SKWORK2 & Transport and mobile machine drivers and operatives & $3.0 \%$ & $2.9 \%$ & $2.6 \%$ \\
\hline UNSKWORK & Elementary occupation & $9.4 \%$ & $10.5 \%$ & $8.8 \%$ \\
\hline \multicolumn{5}{|c|}{ REGION } \\
\hline REGION1 & Ile-de-France (reference) & $17.4 \%$ & $17.2 \%$ & $18.8 \%$ \\
\hline REGION2 & Nord, Champagne-Ardennes, Lorraine, Alsace & $17.1 \%$ & $17.0 \%$ & $17.3 \%$ \\
\hline REGION3 & $\begin{array}{l}\text { Pays de Loire, Bretagne, Centre, Limousin, Aquitaine, } \\
\text { Poitou-Charente }\end{array}$ & $24.6 \%$ & $24.2 \%$ & $21.7 \%$ \\
\hline REGION4 & $\begin{array}{l}\text { Bourgogne, Franche-Comté, Rhône-Alpes, Auvergne, Midi- } \\
\text { Pyrénées, Languedoc }\end{array}$ & $25.2 \%$ & $25.7 \%$ & $26.0 \%$ \\
\hline REGION5 & PACA, Corse & $7.9 \%$ & $8.0 \%$ & $8.5 \%$ \\
\hline
\end{tabular}




\begin{tabular}{|c|c|c|c|c|}
\hline REGION6 & Picardie, Normandie & $7.8 \%$ & $8.0 \%$ & $7.7 \%$ \\
\hline \multicolumn{5}{|c|}{ URBAN UNIT } \\
\hline STRAT1 & Rural area & $26.6 \%$ & $26.4 \%$ & $25.3 \%$ \\
\hline STRAT2 & Small towns & $16.5 \%$ & $16.9 \%$ & $18.0 \%$ \\
\hline STRAT3 & Middle towns & $13.2 \%$ & $13.4 \%$ & $11.9 \%$ \\
\hline STRAT4 & Big towns & $28.9 \%$ & $28.6 \%$ & $29.0 \%$ \\
\hline STRAT5 & Paris (reference) & $14.8 \%$ & $14.7 \%$ & $15.9 \%$ \\
\hline \multicolumn{5}{|c|}{ MARITAL STATUS } \\
\hline SINGFAM & Single parent family & $7.3 \%$ & $6.7 \%$ & $7.2 \%$ \\
\hline COUPLECH2 & Couple with at least two children & $13.9 \%$ & $13.4 \%$ & $13.3 \%$ \\
\hline COUPLECH1 & Couple with one child & $21.2 \%$ & $18.3 \%$ & $18.2 \%$ \\
\hline COUPLENOCH & Couple without children & $28.7 \%$ & $29.8 \%$ & $31.2 \%$ \\
\hline SINGLE & $\begin{array}{l}\text { Single without children (never been in couple, separated or } \\
\text { divorced) }\end{array}$ & $28.9 \%$ & $23.3 \%$ & $22.7 \%$ \\
\hline WIDOWED & Widowed & $12.3 \%$ & $12.8 \%$ & $11.7 \%$ \\
\hline \multicolumn{5}{|c|}{ ATTITUDES AND BEHAVIOURS } \\
\hline EXERCISE & $\begin{array}{l}\text { Frequency of exercise = Never or less than once in a month } \\
\text { Between one and three times in a month } \\
\text { Once a week at least } \\
\text { Several times in a week }\end{array}$ & $\begin{array}{c}64.5 \% \\
5.0 \% \\
12.8 \% \\
17.7 \% \\
\end{array}$ & $\begin{array}{c}65.2 \% \\
5.7 \% \\
12.3 \% \\
16.9 \% \\
\end{array}$ & $\begin{array}{c}65.1 \% \\
6.0 \% \\
13.0 \% \\
15.9 \%\end{array}$ \\
\hline SUBJDIET & $\begin{array}{l}\text { Perception of diet quality }=\text { unbalanced } \\
\text { Not well balanced } \\
\text { Fairly balanced } \\
\text { Well balanced }\end{array}$ & $\begin{array}{c}3.9 \% \\
19.8 \% \\
44.1 \% \\
32.2 \% \\
\end{array}$ & $\begin{array}{r}4.1 \% \\
19.5 \% \\
44.2 \% \\
32.3 \% \\
\end{array}$ & $\begin{array}{r}4.3 \% \\
22.3 \% \\
45.2 \% \\
28.2 \% \\
\end{array}$ \\
\hline LIGHTFAT & $\begin{array}{l}\text { Consume products light in fat }=\text { rarely or never } \\
\text { Sometimes } \\
\text { At least once a week } \\
\text { Every days }\end{array}$ & $\begin{array}{l}51.8 \% \\
18.2 \% \\
8.4 \% \\
21.6 \%\end{array}$ & $\begin{array}{c}48.9 \% \\
19.3 \% \\
8.5 \% \\
23.3 \%\end{array}$ & $\begin{array}{l}28.4 \% \\
10.1 \% \\
21.6 \% \\
39.9 \%\end{array}$ \\
\hline FREESUGAR & $\begin{array}{l}\text { Consume products light in sugar = rarely or never } \\
\text { Sometimes } \\
\text { At least once a week } \\
\text { Every days }\end{array}$ & $\begin{array}{c}66.9 \% \\
11.2 \% \\
5.5 \% \\
16.5 \% \\
\end{array}$ & $\begin{array}{c}64.9 \% \\
11.3 \% \\
5.8 \% \\
18.0 \%\end{array}$ & $\begin{array}{c}24.3 \% \\
7.0 \% \\
13.1 \% \\
55.7 \%\end{array}$ \\
\hline RESTRICT & $\begin{array}{l}\text { Avoid consuming some tasty food products when they are } \\
\text { too rich in fat or sugar }\end{array}$ & $41.2 \%$ & $44.0 \%$ & $52.0 \%$ \\
\hline SODA & $\begin{array}{l}\text { Had drunken at least one glass of a carbo-hydrated drink in } \\
\text { the last day }\end{array}$ & $26.0 \%$ & $22.9 \%$ & $20.6 \%$ \\
\hline ALCOHOL & Had drunken at least one glass of alcohol in the last day & $47.7 \%$ & $50.5 \%$ & $49.2 \%$ \\
\hline
\end{tabular}


Figure A1. (analysis sample)

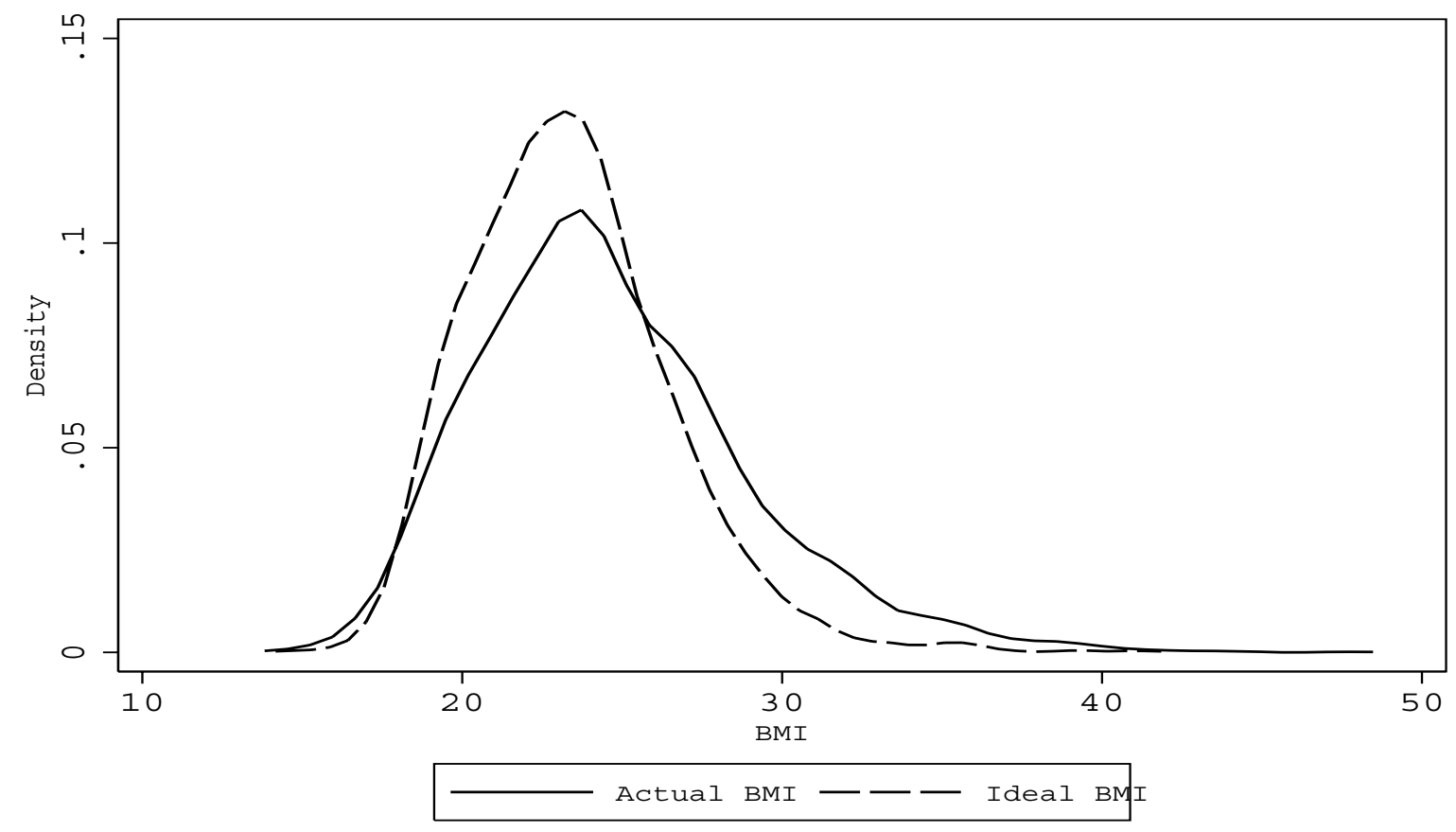

$\underline{\text { Table A2.a. (analysis sample) }}$

\begin{tabular}{|l|c|c|c|}
\cline { 2 - 4 } \multicolumn{1}{c|}{} & \multicolumn{3}{c|}{ Weight satisfaction } \\
\cline { 2 - 4 } \multicolumn{1}{c|}{} & BMI>ideal BMI & BMI = ideal BMI & BMI $<$ ideal BMI \\
\hline Underweight: $B M I<18.5$ & $0.51 \%(10)$ & $4.60 \%(63)$ & $30.19 \%(64)$ \\
\hline Healthy weight: $18.5 \leq B M I<25$ & $42.27 \%(826)$ & $72.50 \%(994)$ & $69.34 \%(147)$ \\
\hline Overweight: $25 \leq B M I<30$ & $40.17 \%(785)$ & $19.40 \%(266)$ & $0.47 \%(1)$ \\
\hline Obese: $30<B M I$ & $17.04 \%(333)$ & $3.50 \%(48)$ & $0 \%(0)$ \\
\hline Total & $100 \%(1954)$ & $100 \%(1371)$ & $100 \%(212)$ \\
\hline
\end{tabular}

Note: except the last row, these figures should be read as conditional probabilities Pr(col|row). For instance, 30.19\% of those who would like to gain weight are medically underweight. The absolute frequency (number of observations) is enclosed in parentheses.

Table A2.b. (analysis sample)

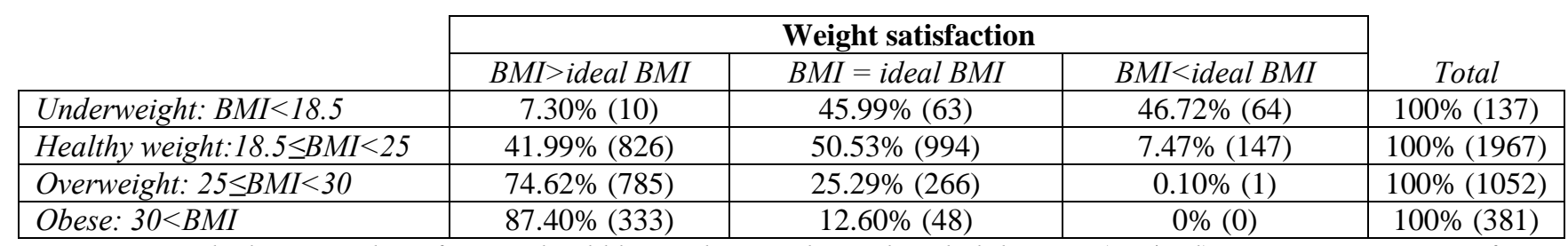

Note: except the last row, these figures should be read as conditional probabilities $\operatorname{Pr}($ row $\mid$ col). For instance, $7.3 \%$ of those who are medically underweight would like to slim. The absolute frequency (number of observations) is enclosed in parentheses. 


\section{Appendix B. Results}

Notes for all tables: $*=$ significant at the $10 \%$ level, $* *=$ significant at the $5 \%$ level, $* * *=$ significant at the $1 \%$ level. Standard errors in parenthesis.

Table B1. - Ideal Body Weight as a predictor of food attitudes ( $\mathrm{N}=3537)$

\begin{tabular}{|c|c|c|c|c|c|c|c|}
\hline & EXERCISE & SUBJDIET & LIGHTFAT & FREESUGAR & RESTRICT & SODA & ALCOHOL \\
\hline Model & \multicolumn{4}{|c|}{ Ordered probit } & \multicolumn{3}{|c|}{ Probit } \\
\hline UNDERW & $\begin{array}{l}-1.152 \\
(0.936)\end{array}$ & $\begin{array}{c}-1.705 * * \\
(0.791)\end{array}$ & $\begin{array}{c}-3.186^{* * *} \\
(0.984)\end{array}$ & $\begin{array}{l}-1.369 \\
(1.053)\end{array}$ & $\begin{array}{c}-2.472 * * \\
(1.002)\end{array}$ & $\begin{array}{l}2.593 * * * \\
(0.991)\end{array}$ & $\begin{array}{l}-0.505 \\
(0.941)\end{array}$ \\
\hline OVERW & $\begin{array}{l}-0.380 \\
(0.441)\end{array}$ & $\begin{array}{c}-2.202 * * * \\
(0.360)\end{array}$ & $\begin{array}{c}0.996 * * * \\
(0.376)\end{array}$ & $\begin{array}{c}1.748 * * * \\
(0.397)\end{array}$ & $\begin{array}{c}1.749 * * * \\
(0.430)\end{array}$ & $\begin{array}{c}0.133 \\
(0.483)\end{array}$ & $\begin{array}{c}-0.889 * * \\
(0.439)\end{array}$ \\
\hline $\begin{array}{l}\log (\text { Prescription: } \\
\left.\mathrm{E}\left(\mathrm{W}^{*} \mid \Psi(\mathrm{Q})\right)\right)\end{array}$ & $\begin{array}{l}1.967^{*} \\
(1.047)\end{array}$ & $\begin{array}{l}-1.304 \\
(0.902)\end{array}$ & $\begin{array}{c}0.037 \\
(0.955)\end{array}$ & $\begin{array}{c}-2.349 * * \\
(1.038)\end{array}$ & $\begin{array}{l}-0.991 \\
(1.078)\end{array}$ & $\begin{array}{c}0.961 \\
(1.251)\end{array}$ & $\begin{array}{l}-1.427 \\
(1.081)\end{array}$ \\
\hline Log(Actual BMI: W) & $\begin{array}{c}-0.670 * * * \\
(0.211)\end{array}$ & $\begin{array}{l}-0.245 \\
(0.176) \\
\end{array}$ & $\begin{array}{c}0.595 * * * \\
(0.185)\end{array}$ & $\begin{array}{c}0.947 * * * \\
(0.198)\end{array}$ & $\begin{array}{c}0.238 \\
(0.207) \\
\end{array}$ & $\begin{array}{l}-0.038 \\
(0.239) \\
\end{array}$ & $\begin{array}{l}-0.166 \\
(0.210) \\
\end{array}$ \\
\hline Log(HEIGHT) & $\begin{array}{l}-0.561 \\
(0.571)\end{array}$ & $\begin{array}{l}-0.218 \\
(0.493)\end{array}$ & $\begin{array}{l}1.011^{* *} \\
(0.515)\end{array}$ & $\begin{array}{l}1.049 * \\
(0.560)\end{array}$ & $\begin{array}{c}0.739 \\
(0.581)\end{array}$ & $\begin{array}{c}0.561 \\
(0.664)\end{array}$ & $\begin{array}{c}0.663 \\
(0.588)\end{array}$ \\
\hline Controls & $\begin{array}{l}\text { Log(INCN } \\
\text { EMPPRIV }\end{array}$ & $\begin{array}{l}\text { SEX, AGE/1 } \\
\text { MPPRIV2, SK } \\
\text { SINGLE, }\end{array}$ & $\begin{array}{l}\text { GE/10 })^{2}, \text { FARI } \\
\text { RK1, SKWOR } \\
\text { FAM, WIDOW }\end{array}$ & $\begin{array}{l}\text { RS, OWNERS, } \\
\text { UNSKWORK, Y } \\
\text {, STRAT1-STR }\end{array}$ & $\begin{array}{l}\text { DPUB1, MIDF } \\
\text { SCHOOL, CO } \\
44, \text { REGION2- }\end{array}$ & $\begin{array}{l}\text { 2, MIDPRI } \\
\text { LECH1, CO } \\
\text { GION6 }\end{array}$ & $\begin{array}{l}\text { EMPPUB, } \\
\text { LENOCH, }\end{array}$ \\
\hline
\end{tabular}


Table B2 - The determinants of ideal BMI (Dependent variable : $\log \left(\mathrm{W}^{*}\right) ; \mathrm{N}=1954$ ).

\begin{tabular}{|c|c|c|c|c|c|}
\hline Method / Specification & OLS / 1 & OLS / 2 & GMM / 3 & GMM / 4 & GMM / 5 \\
\hline Log(Prescription) & & $0.134 *(0.027)$ & \multirow{2}{*}{$\begin{array}{c}0.775 *(0.000) \\
0.269 *(0.046)\end{array}$} & \multirow[t]{2}{*}{$1.042 * *(0.000)$} & $-0.201(0.764)$ \\
\hline $\log ($ Actual BMI $)$ & & $0.635 * *(0.000)$ & & & $0.587 * *(0.000)$ \\
\hline SEX & $0.110^{* *}(0.000)$ & $0.036^{* *}(0.000)$ & & & $0.074(0.278)$ \\
\hline AGE/10 & $0.052 * *(0.000)$ & $-0.005(0.461)$ & & & $0.019(0.652)$ \\
\hline$(\mathrm{AGE} / 10)^{2}$ & $-0.003 * *(0.008)$ & $0.001 *(0.036)$ & & & $-0.000(0.941)$ \\
\hline FARMERS & $0.041 *(0.011)$ & $0.007(0.462)$ & & & $0.031(0.492)$ \\
\hline OWNERS & $0.005(0.684)$ & $-0.011(0.078)$ & & & $-0.000(0.981)$ \\
\hline MIDPUB1 & $0.003(0.804)$ & $-0.008(0.130)$ & & & $-0.005(0.434)$ \\
\hline MIDPUB2 & $0.007(0.562)$ & $-0.000(0.997)$ & & & $0.007(0.613)$ \\
\hline MIDPRIV & $0.021(0.104)$ & $-0.001(0.933)$ & & & $0.010(0.604)$ \\
\hline EMPPUB & $0.026 *(0.011)$ & $-0.006(0.333)$ & & & $0.012(0.712)$ \\
\hline EMPPRIV1 & $-0.005(0.608)$ & $-0.016 * *(0.004)$ & & & $-0.010(0.350)$ \\
\hline EMPPRIV2 & $0.013(0.254)$ & $-0.013 *(0.043)$ & & & $0.001(0.957)$ \\
\hline SKWORK1 & $0.023 *(0.035)$ & $-0.010(0.132)$ & & & $0.007(0.815)$ \\
\hline SKWORK2 & $0.041 *(0.013)$ & $-0.003(0.749)$ & & & $0.026(0.628)$ \\
\hline UNSKWORK & $0.018(0.133)$ & $-0.020 * *(0.005)$ & & & $0.001(0.976)$ \\
\hline YRSCHOOL & $-0.002 * *(0.005)$ & $0.000(0.802)$ & & & \\
\hline $\log ($ INCMIN) & $-0.006(0.283)$ & $0.004(0.200)$ & $0.003(0.529)$ & $-0.003(0.567)$ & $0.003(0.423)$ \\
\hline COUPLECH1 & $0.001(0.908)$ & $-0.003(0.536)$ & $-0.006(0.325)$ & $-0.005(0.541)$ & $-0.001(0.818)$ \\
\hline COUPLENOCH & $0.005(0.528)$ & $-0.004(0.315)$ & $-0.004(0.504)$ & $-0.003(0.686)$ & $-0.000(0.953)$ \\
\hline SINGLE & $-0.006(0.459)$ & $-0.004(0.363)$ & $-0.009(0.133)$ & $-0.012(0.115)$ & $-0.002(0.820)$ \\
\hline SINGFAM & $-0.034 * *(0.001)$ & $-0.017 * *(0.002)$ & $-0.024 * *(0.004)$ & $-0.030 * *(0.003)$ & $-0.018 *(0.011)$ \\
\hline WIDOWED & $0.037 * *(0.000)$ & $0.007(0.164)$ & $0.018 *(0.031)$ & $0.025 *(0.019)$ & $0.014(0.218)$ \\
\hline \multicolumn{6}{|c|}{ Other control variables $H$ : constant, STRAT1-STRAT4, REGION2-REGION6, $\log ($ HEIGHT) } \\
\hline \multicolumn{3}{|c|}{ Excluded instruments } & \multicolumn{3}{|c|}{$\mathrm{W}^{\mathrm{g}+}, \mathrm{W}^{\mathrm{g}-}$, YRSCHOOL (except for GMM/4), MDENTS (except for GMM/4) } \\
\hline \multicolumn{3}{|c|}{ Relative bias (Cragg-Donald statistics) } & $>30 \%(4.16)$ & $0 \%(586.7)$ & $>30 \%(3.85)$ \\
\hline \multicolumn{3}{|c|}{ Anderson-Rubin statistics } & p-value: 0.001 & p-value: 0.000 & p-value: 0.001 \\
\hline \multicolumn{3}{|c|}{ Hansen's over-identification test } & p-value: 0.199 & p-value: 0.546 & p-value: 0.748 \\
\hline
\end{tabular}


Table B3 - Regressions by gender (specification 3, GMM estimator)

\begin{tabular}{|c|c|c|}
\hline & Women $(\mathrm{N}=1282)$ & Men (N=672) \\
\hline Log(Prescription) & $0.715 * *(0.000)$ & $-0.232(0.318)$ \\
\hline Log(Actual BMI) & $0.329 * *(0.002)$ & $0.957 * * *(0.000)$ \\
\hline Log(INCMIN) & $0.001(0.911)$ & $0.013 *(0.013)$ \\
\hline COUPLECH1 & $-0.008(0.242)$ & $0.010(0.209)$ \\
\hline COUPLENOCH & $-0.009(0.194)$ & $0.015 *(0.045)$ \\
\hline SINGLE & $-0.011(0.108)$ & $0.008(0.259)$ \\
\hline SINGFAM & $-0.025 * *(0.006)$ & $-0.013(0.476)$ \\
\hline WIDOWED & $0.018(0.064)$ & $0.008(0.581)$ \\
\hline \multicolumn{3}{|c|}{ Other control variables $H$ : constant, STRAT1-STRAT4, REGION2-REGION6, log(HEIGHT) } \\
\hline Excluded instruments & \multirow{4}{*}{$\begin{array}{c}\text { YRSCHOOL, MDENTS, } \mathrm{W}^{\mathrm{g}+}, \mathrm{W}^{\mathrm{g}-} \\
\text { 20-30\% (5.27) } \\
\text { p-value: } 0.0001 \\
\text { p-value: } 0.450\end{array}$} & \multirow{4}{*}{$\begin{array}{c}\text { YRSCHOOL, MOBESE, } \mathrm{W}^{\mathrm{g}+}, \mathrm{W}^{\mathrm{g}-} \\
>30 \%(2.19) \\
\text { p-value: } 0.023 \\
\text { p-value: } 0.176\end{array}$} \\
\hline Relative bias (Cragg-Donald statistics) & & \\
\hline Anderson-Rubin statistics & & \\
\hline Hansen's over-identification test & & \\
\hline
\end{tabular}


Table B4 - Sensitivity analysis (specification 3, GMM estimator, point-estimates)

\begin{tabular}{|c|c|c|c|c|c|c|}
\hline 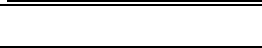 & \multicolumn{3}{|c|}{ Women } & \multicolumn{3}{|c|}{ Men } \\
\hline Age Window & 2 & 5 & 10 & 2 & 5 & 10 \\
\hline & \multicolumn{6}{|c|}{ Reference-group: same sex, same occupation, age window. Instruments as in Table B3. } \\
\hline Log(Prescription) & $0.696 * * *$ & $0.715 * * *$ & $0.757 * * *$ & 0.076 & -0.232 & -0.176 \\
\hline $\log ($ Actual BMI) & $0.343 * * *$ & $0.329 * * *$ & $0.295 * *$ & $0.746^{* * *}$ & $0.957 * * *$ & $0.855^{* * *}$ \\
\hline Relative bias & $\approx 30 \%$ & $20-30 \%$ & $20-30 \%$ & $>>30 \%$ & $>30 \%$ & $>30 \%$ \\
\hline Hansen's test & 0.245 & 0.450 & 0.119 & 0.0002 & 0.176 & 0.296 \\
\hline \multirow[t]{2}{*}{$\mathrm{N}$} & 1009 & 1282 & 1245 & 403 & 672 & 728 \\
\hline & \multicolumn{6}{|c|}{$\begin{array}{c}\text { Reference-group: same sex, same education, age window }=5 \text { years. YRSCHOOL not used as IV. Other } \\
\text { instruments as in Table B3. }\end{array}$} \\
\hline Log(Prescription) & \multicolumn{3}{|c|}{$0.728 * * *$} & \multicolumn{3}{|c|}{-0.169} \\
\hline $\log ($ Actual BMI) & \multicolumn{3}{|c|}{$0.303 *$} & \multicolumn{3}{|c|}{$0.900 * * *$} \\
\hline Relative bias & \multicolumn{3}{|c|}{$>>30 \%$} & \multicolumn{3}{|c|}{$>>30 \%$} \\
\hline Hansen's test & \multicolumn{3}{|c|}{0.175} & \multicolumn{3}{|c|}{0.333} \\
\hline $\mathrm{N}$ & \multicolumn{3}{|c|}{1245} & \multicolumn{3}{|c|}{728} \\
\hline & \multicolumn{6}{|c|}{ Reference-group: same sex, age window = 5 years. Instruments as in Table B3. } \\
\hline Log(Prescription) & \multicolumn{3}{|c|}{$0.524 * * *$} & \multicolumn{3}{|c|}{-0.022} \\
\hline $\log ($ Actual BMI) & \multicolumn{3}{|c|}{$0.490 * * *$} & \multicolumn{3}{|c|}{$0.784 * * *$} \\
\hline Relative bias & & \multicolumn{3}{|c|}{$20-30 \%$} \\
\hline Hansen's test & \multicolumn{3}{|c|}{0.197} & \multicolumn{3}{|c|}{0.313} \\
\hline $\mathrm{N}$ & \multicolumn{3}{|c|}{1341} & \multicolumn{3}{|c|}{767} \\
\hline
\end{tabular}

Note: estimates in italics are not robust (rejection of the over-identifying restrictions) 